\title{
Surgically-induced brain injury: where are we now?
}

\author{
Zachary D. Travis ${ }^{1 *} \mathbb{D}$, Prativa Sherchan², William K. Hayes ${ }^{1}$ and John H. Zhang ${ }^{2,3}$
}

\begin{abstract}
Neurosurgical procedures cause inevitable brain damage from the multitude of surgical manipulations utilized. Incisions, retraction, thermal damage from electrocautery, and intraoperative hemorrhage cause immediate and long-term brain injuries that are directly linked to neurosurgical operations, and these types of injuries, collectively, have been termed surgical brain injury (SBI). For the past decade, a model developed to study the underlying brain pathologies resulting from SBI has provided insight on cellular mechanisms and potential therapeutic targets. This model, as seen in a rat, mouse, and rabbit, mimics a neurosurgical operation and causes commonly encountered post-operative complications such as brain edema, neuroinflammation, and hemorrhage. In this review, we elaborate on SBI and its clinical impact, the SBI animal models and their clinical relevance, the importance of applying therapeutics before neurosurgical procedures (i.e., preconditioning), and the new direction of applying venom-derived proteins to attenuate SBI.
\end{abstract}

Keywords: Brain injury, Cerebral edema, Preconditioning, Neurotherapeutics, Venom therapies

\section{Background}

Damage to brain tissue occurs frequently at the periphery of a resection site. The delicate and intricate architecture of the brain presents severe challenges for neurosurgery; in fact, some specific neurosurgical operations where the brain stem, spinal cord, and posterior cranial vault are involved have been linked to post-operative neurological deficits, no matter how precise and careful the surgeon is [1-3].

After a craniotomy has been performed and the meninges resected, the brain is extremely susceptible to mechanical injury. Surgical brain injury (SBI) comprises a form of injury that inadvertently results from damaged brain tissue at the perisurgical site due to neurosurgical maneuvers such as incision, retraction, and electrocauterization, all of which are essential surgical techniques. Although, through modern science, there has been a decrease in the level of invasiveness with endoscopic surgeries and stereotaxic-guided procedures, coupled with an increase in the specificity of post-operative care, there remains unavoidable injury which negatively

\footnotetext{
*Correspondence: zacharydtravis@gmail.com

${ }^{1}$ Department of Earth and Biological Sciences, School of Medicine, Loma Linda University, Loma Linda, CA 92354, USA

Full list of author information is available at the end of the article
}

impacts the patient, their family, and the health care system in the short and long term [4].

Brain edema, neuroinflammation, cellular death, and hemorrhage are post-operative complications that develop (within hours and continue for days after injury) following neurosurgical procedures and may lead to further injury by triggering secondary pathways that ultimately lead to long-term complications and neurological deficits [5-10]. To date, complications arising from SBI are not explicitly treated and are left to heal on their own. Therapies which directly target SBI are lacking, leaving a gap in postcare treatment. SBI not only poses a risk to all patients who undergo brain surgery but also eliminates certain patients from specific surgical procedures which are deemed more risky.

Every year, 13.8 million patients around the globe require surgery due to traumatic brain injury (TBI), stroke-related conditions, tumors, hydrocephalus, and epilepsy [11]. Millions of these surgical cases are in low- and middle-income countries where acute care is hard to come by. It is imperative that we look toward a potential therapeutic which can diminish post-operative complications which may not only have a positive effect on the patient but also on low- and middle-income countries. Osmotic agents, diuretics, and steroids have been used to reduce the post-operative effects

(c) The Author(s). 2019 Open Access This article is distributed under the terms of the Creative Commons Attribution 4.0 International License (http://creativecommons.org/licenses/by/4.0/), which permits unrestricted use, distribution, and 
of these injuries and decrease the neurological deficits that may occur [12]. Steroids successfully attenuate tumorigenic edema, but in CRASH trials, steroids showed harmful effects after traumatic brain injury [13]. Currently, there are no standard treatment regimens to prevent the inevitable injuries associated with routine neurosurgical procedures [14].

Complications that lead to neurological deficits often result in a financial and legal quagmire. Patients and their families may suffer from devastating financial burdens. Physicians, and especially surgeons, have become all too familiar with a toxic medical-legal climate that has led to defensive medical practice by those in highrisk specialties. In a Journal of the American Medical Association study, nearly $75 \%$ of polled neurosurgeons confessed to avoiding particular procedures or high-risk patients out of the fear of malpractice suits being filed against them $[15,16]$. Furthermore, a UK survey done by the Medical Defense Union stated that damage to underlying brain structures is the commonest complication for which patients successfully sue surgeons [17]. Even if there is no serious complication, neurosurgical patients have to be monitored closely, which translates into longer hospital stays and rising costs for the patient, healthcare system, and society. Diminishing perioperative risks may allow for an expansion of more aggressive surgical interventions and more patients being suitable for treatment.

The purpose of this review is to discuss the pathophysiology of SBI, animal models currently being used for investigation, and potential therapeutics that could provide neuroprotection for patients.

\section{Animal model for surgical brain injury}

Animal models for brain injury allow investigators to study cellular signaling mechanisms by applying molecular techniques to the affected brain tissue. Upon successful determination of signaling pathways, key molecular targets for potential neuroprotection may be investigated [18]. First seen in 2006, Frontczak-Baniewicz et al. [19] demonstrated that an in vivo frontal temporal model could be used to study SBI. Jadhav et al. [14] created a replicable in vivo model which has been utilized for the past decade to study brain injury caused by neurosurgical procedures. This frontal lobe resection model is not intended to mimic any specific neurosurgery operation, rather it allows researchers to simulate a more general SBI by causing both cortical and parenchymal damage. This model produces a certain amount of brain tissue loss and injury that causes the neuronal death, bloodbrain barrier (BBB) dysfunction, and brain edema that occur during routine neurosurgical operations. Previous reports have documented that the SBI animal model has localized brain edema and BBB disruption in the brain tissue surrounding the resection. The model allows researchers to study the post-operative complications of surgically induced brain injury, and the molecular mechanisms and signaling pathways involved, because it provides for consistently measurable edema via brain water content in the perilesional tissue. It also promotes measurement of neurological deficits following SBI, which is critical when investigating therapies for patients.

Investigators have adopted this model to rats, mice, and even rabbits. In brief, after anesthetizing the animal, the investigator exposes the frontal skull and then removes a bone flap to expose the right frontal lobe of the brain. After moving aside the dura, the investigator then makes two incisions to free the right frontal lobe from its surrounding tissue. Intraoperative packing and saline irrigation are used to control bleeding and induce hemostasis before placing the dura and skull cap back in their original position and suturing the skin (Fig. 1).

\section{Pathophysiology of surgical brain injury}

As previously mentioned, SBI comprises a two-stage injury. Primary injury results from the mechanical forces during surgery, which are largely unavoidable, though minimally invasive techniques are increasingly utilized. Secondary injury arises from the cascade of cellular and metabolic processes put into motion because of the primary injury [20] (Fig. 2). This cellular cascade chiefly involves inflammatory molecules such as cytokines and prostaglandins. A key player in the propagation of the secondary injury is the breakdown of the blood-brain barrier (BBB).

The BBB is part of a complex and intricate barrier system which is tasked with maintaining homeostasis for the neural microenvironment [21, 22]. Three barriers

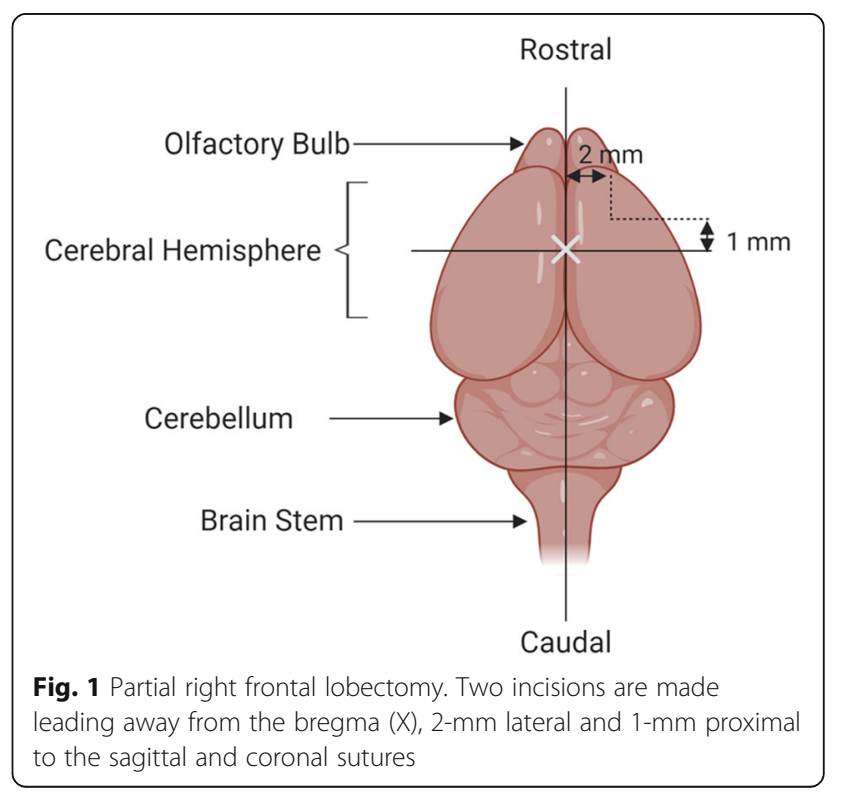




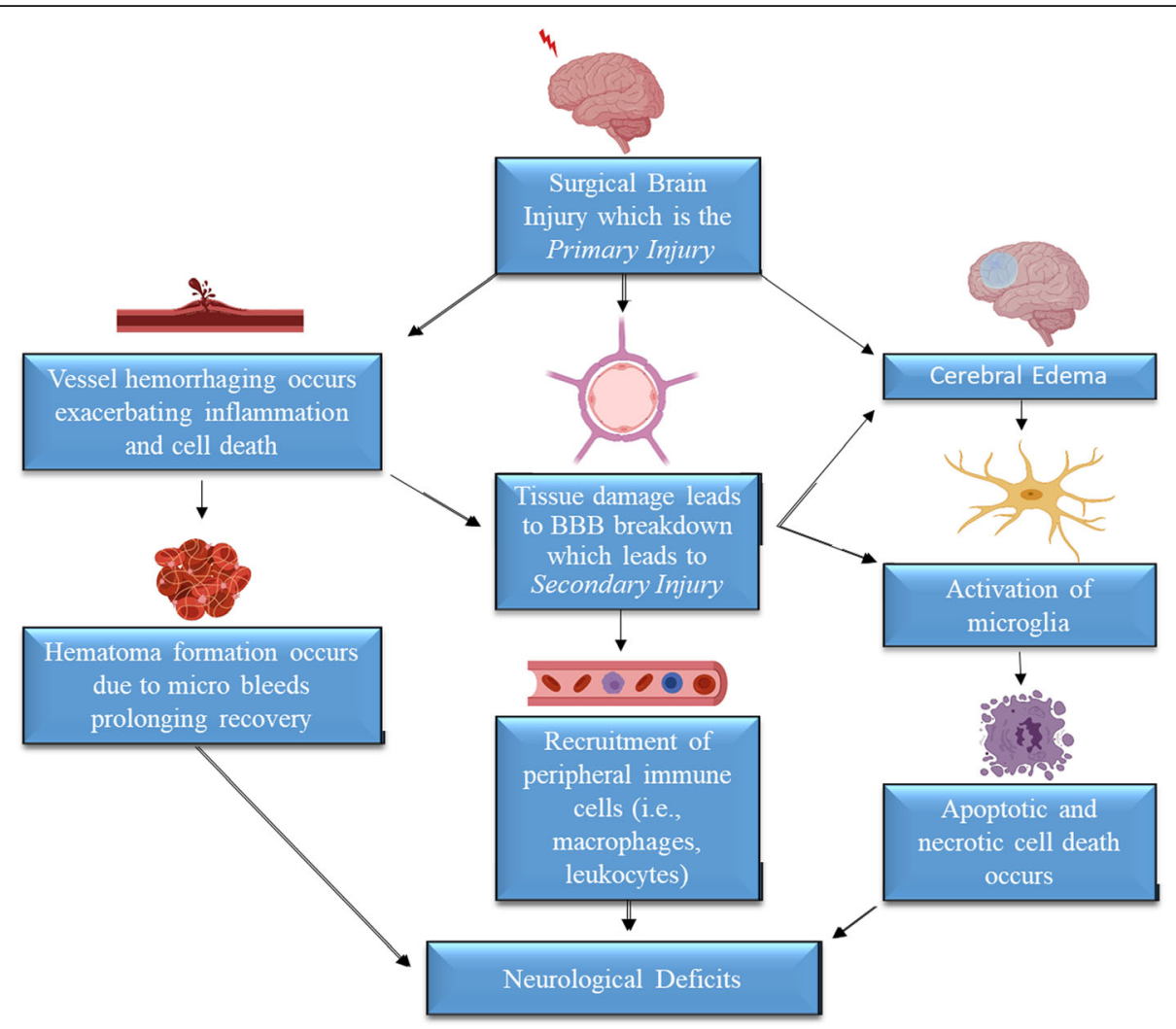

Fig. 2 Primary and secondary injury due to SBI

actually exist between the blood and the central nervous system (CNS): the BBB, blood-cerebral spinal fluid (CSF) barrier, and the arachnoid barrier. The BBB is created by the endothelial cells that form the wall of the brain capillaries; the blood-CSF barrier is formed by the epithelial cells of the choroid plexus; and the arachnoid barrier is composed of the avascular arachnoid epithelium [21]. The BBB functions as a result of three properties: a physical barrier composed of tight junctions between cells reducing flux via the intercellular cleft or paracellular pathway; a transport barrier which mediates the movement of solutes; and a metabolic barrier [22]. All three properties of this collective barrier can be modulated either through homeostatic pathways or pathologies. Disruption to the BBB has been shown to increase post-operative brain edema and worsen neurological function. Trauma, for example, can generate bradykinin, a mediator of inflammation, which stimulates production and release of interleukin-6 (IL-6) from astrocytes, which in turn leads to opening of the BBB [23]. Without stable fluidity provided by the barrier, the CNS cannot function.

Four pathophysiological features of SBI merit special consideration: cerebral edema, neuroinflammation, cell death, and hemorrhage and will be explained in more depth. These pathologies are implicated in exacerbating the healing process for patients.
Cerebral edema is a common pathophysiological formation following surgery. Cerebral edema comprises excess accumulation of water in the intra- and/or extracellular spaces of the brain [24]. Cerebral edema results from a combination of endothelial cell damage, tight junction disruption, and abnormal transcellular transport [25]. Damage to cells and blood vessels triggers a multitude of cellular cascades, which amplifies injury. Calcium and sodium channels become activated, which causes a fluid imbalance and triggers cytotoxic processes. An inflammatory response is mounted, and microglial cells release free radicals and proteases which further the attack on cell membranes and capillaries [26]. The free radicals are toxic to cells, and macrophages, as well as activated microglial cells, form nitric oxide (NO), which is an additional source of free radicals. When the CNS is injured, mediators such as glutamate and extracellular potassium are released which causes swelling leading to damage of nerve cells [24].

Cerebral edema has been partitioned into three categories-vasogenic, cytotoxic, and interstitial edema. Vasogenic cerebral edema is the term used to describe the influx of fluid and solutes into the brain through an inadequate $\mathrm{BBB}$, which primarily affects the white matter [27]. Vasogenic cerebral edema is the most common type of brain edema, and originates from the increased 
permeability of the capillary endothelial cells. The breakdown of the BBB allows for the movement of proteins and solutes that were originally in the intravascular space through the capillary wall into the extracellular space. Cytotoxic edema describes a cellular swelling that affects primarily the gray matter, and is seen in conditions such as head injury and hypoxia [28]. Cytotoxic edema is caused by swelling of glia, neurons, and endothelial cells, and begins within minutes after an insult [29]. Interstitial edema is known to occur in hydrocephalus patients and occurs when outflow of CSF is obstructed, leading to interventricular and eventually intracerebral pressure increase [30].

Brain edema leads to brain swelling. Clinical studies indicate that brain water content is a good indicator of brain swelling resulting from the edema. A $1 \%$ increase in brain water content is equivalent to a $4.3 \%$ increase in brain tissue volume [31, 32]. Rodent studies indicate that the brain water content of tissue surrounding the resection site increases by $3 \%$ or more during the first $72 \mathrm{~h}$ following surgery, and gradually resolves within a week after surgery [33-35]. As stated by the Monro-Kellie hypothesis, the totality of elements inside the skull is composed of the brain, CSF, and blood [36]. These three entities need to remain constant because of the skull's rigidity. If, for example, there is excessive water formation, the brain and blood vessels surrounding the brain will be compressed. Cerebral edema leads to the expansion of brain volume against an enclosed skull and an increase in intracranial pressure (ICP). Elevated ICP can cause herniation, and can also decrease cerebral perfusion pressure, which promotes cerebral ischemia [36].

Neuroinflammation is a key player in the progression of brain edema after neurosurgical procedures. Previous SBI studies have successfully demonstrated that neuroinflammation is propagated through pro-inflammatory cytokines, activation of microglia, and infiltration of non-resident immune cells to the site of injury $[8,18$, 37, 38]. Infiltrated peripheral immune cells release inflammatory mediators and promote oxidative stress and cell death, which contributes to progression of the injury $[39,40]$. Identifying drug targets toward improving functional outcomes post-TBI requires a better understanding of neuroinflammation, including BBB dysfunction, activation of brain resident microglia and astrocytes, secretion of inflammatory mediators, and subsequent recruitment of peripheral immune cells [40-42]. When the BBB is disrupted, and the injured brain is infiltrated by peripherally derived immune cells (i.e., neutrophils and macrophages), resident astrocytes and microglia in the brain are activated.

Cell death, specifically apoptotic and necrotic cell death, has been noted in SBI. Neuronal and glial cell deaths, as well as axonal injury, are the main contributors to the overall pathology of TBI [43]. Matchett et al.
[33] demonstrated apoptotic neuronal death in an SBI model. Furthermore, Sulejczak et al., [10] demonstrated that neuronal apoptosis was accompanied by astrogliosis at the site of resection. In TBI models, apoptotic and necrotic neurons been identified not only at the site of injury post-trauma but also in regions remote from the site of injury days and weeks after trauma [26].

Hemorrhage is a critical issue in neurosurgery and is implicated in contributing to SBI $[9,44]$. Firstly, intraoperative bleeding causes local ischemic insult and systemically plagues the cardiovascular system. While electrocauterization effectively controls bleeding and allows surgeons to be more invasive, healthy tissue becomes damaged by thermal injury. Secondly, SBI causes damage to the brain parenchyma, which damages the cerebral microvessels and leads to neurovascular unit pathophysiology. Disruption of the walls of the microvessels in the BBB activates the coagulation cascade. Since the integrity of the BBB becomes compromised after injury, the proteins thrombin, albumin, and fibrinogen can now enter the brain which causes neuroinflammation and apoptosis. Similar to cerebral edema, even a small increase in blood volume will cause the brain to herniate, leading to life-threatening complications.

Though hematoma formation can be mitigated through proper surgical management, its formation can contribute the propagation of neurological deficits [45]. Microbleeds that occur in the periphery may not be as detrimental as a bleed that is in the brain because of the limited space for expansion. Hematoma formation can increase pressure and force herniation to occur. On a cellular level, the presence of a hematoma is known to activate microglia and the complement cascade. As aforementioned, these two systems lead to an increase in inflammation and damage to healthy unaffected tissue. Limiting the amount of intraoperative bleeding may also reduce the size of a hematoma leading to more positive patient outcomes.

\section{Neurotherapeutics and preconditioning in surgical brain injury}

Currently, clinical management of surgical brain injury is limited to nonspecific post-operative care (e.g., osmotherapy (mannitol, glycerol), diuretics, corticosteroids, and hyperventilation). Many promising therapeutic agents and strategies to mitigate complications of SBI have been evaluated experimentally in animal models (summarized in Table 1), with nearly all of these studies utilizing pre- or post-surgical treatments. Because of the electability of many neurosurgeries, with surgeries scheduled in advance, SBI presents a unique opportunity to test neuroprotection that may prove clinically relevant. In the following sections, we expand on the concept of preconditioning and propose the use of venom-derived proteins as a preconditioning therapy for SBI. 

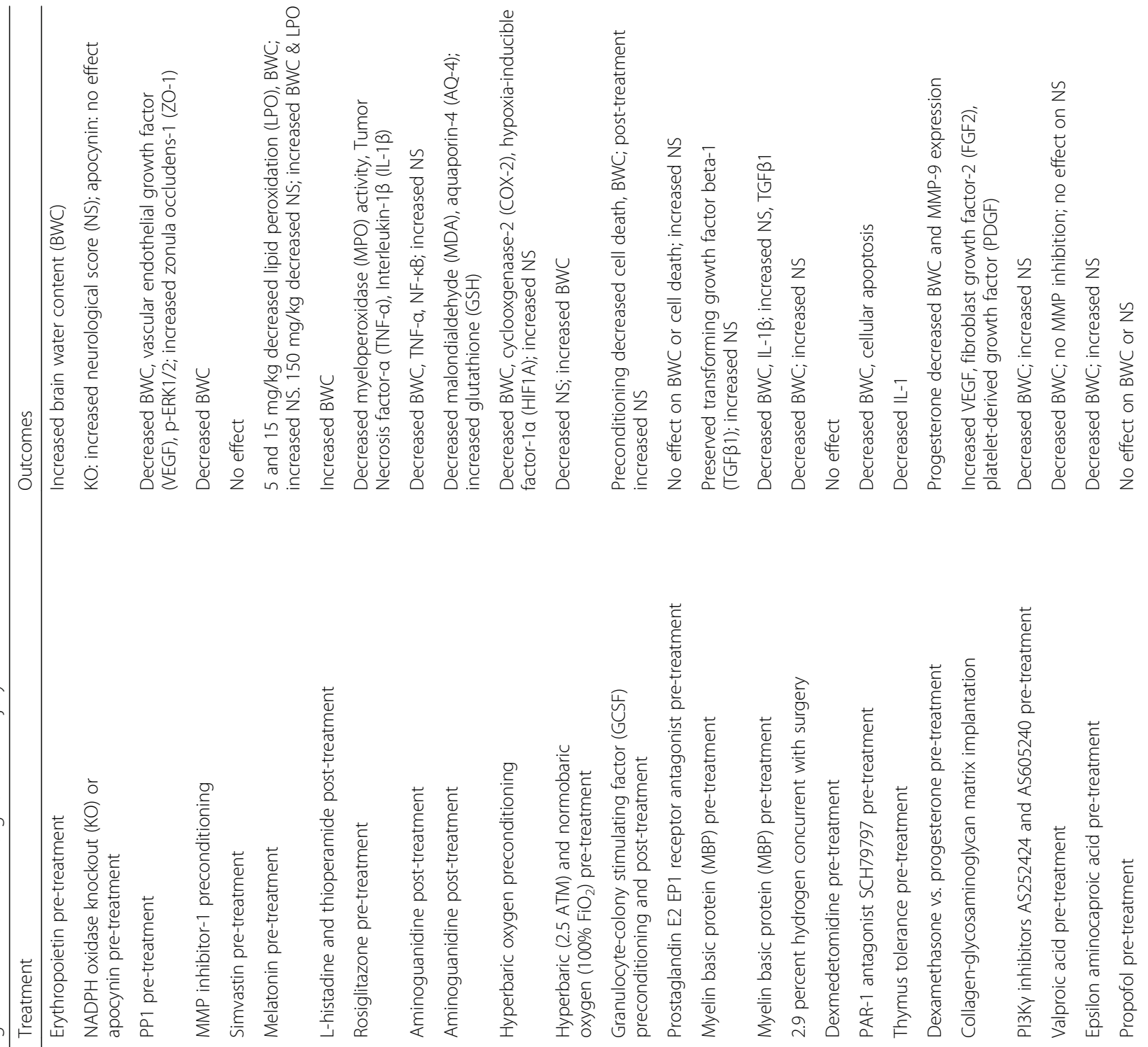


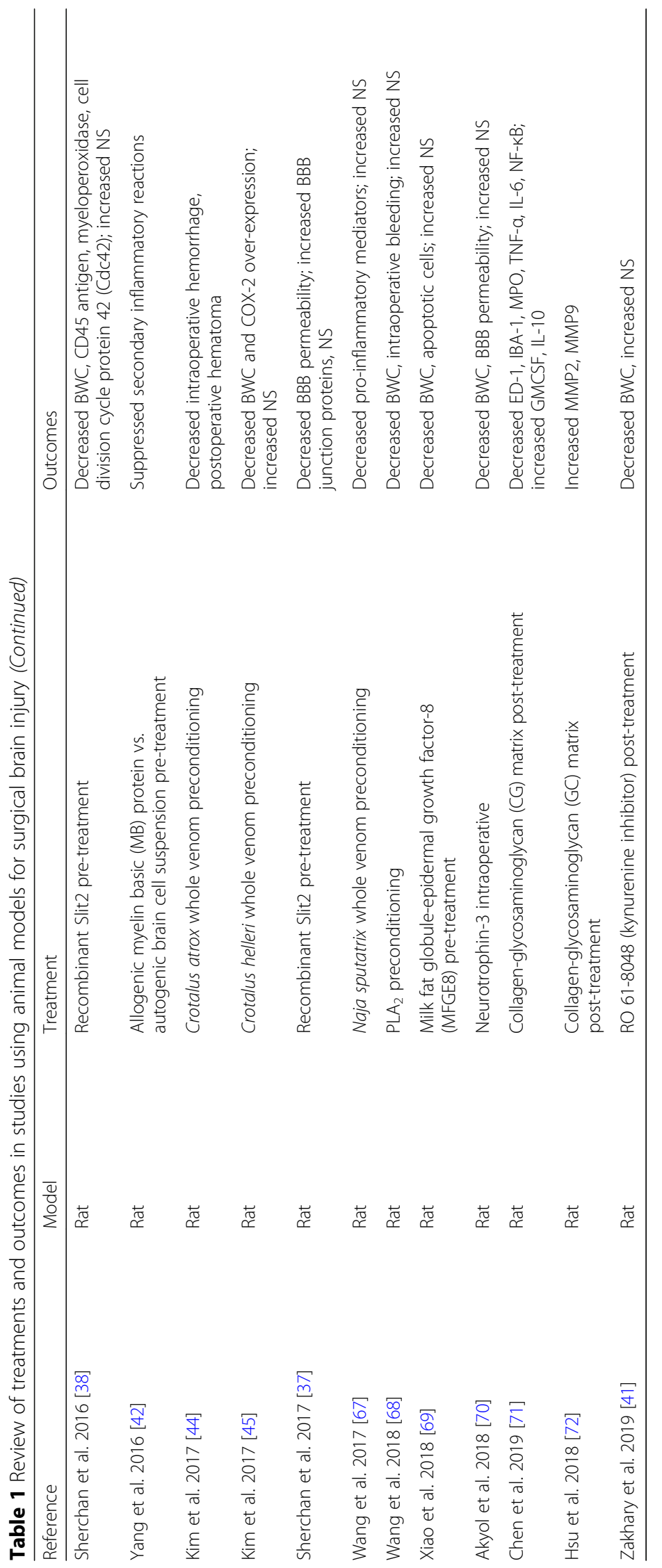


Preconditioning for SBI While preconditioning (PC) studies have demonstrated promising neuroprotective effects for several animal models of different forms of brain injury [35, 44, 45, 67, 68], it has often been noted that clinical translation is limited since many injuries occur spontaneously. In the last few decades, the potential of PC, especially for scheduled (or elective) surgeries, has become a real focus in hopes of developing an effective therapy. PC is an approach that utilizes what would be normally damaging/toxic therapies which, when given in sub-toxic amounts, induce minimal injury while provoking the body's innate protective response, thereby reducing possible damage from a future major insult [73]. PC therapies exist for several stroke and brain injury models. For example, hypoxic/ischemic-PC has been successful in providing neuroprotection in models of stroke [74-77].

To date, more than 30 substances or treatments have been investigated as therapeutic options in SBI (Table 1). Such treatments have been administered before surgery, after surgery, and utilized in a preconditioning manner. Investigators have been able to give insight into the pathology, cellular mechanism of action, and where areas of therapeutic focus should be for treating SBI.

Now, with evidence supporting the efficacy of PC [34, 67], the need remains to investigate a translational therapy. Because of the recent discoveries of snake venom $\mathrm{PC}$ and a further understanding of the mechanism driving these protective effects, we have focused our attention on specific venom protein components which we believe can provide protective effects for edema and hemorrhage.

Venom therapies For many centuries, mankind has utilized the deadly venoms from animals as either weaponry or medical therapies. In 326 B.C.E., Alexander the Great's army encountered arrows dipped in Russell's viper (Daboia russelii) venom in India [78]. One of the first recorded medical uses of venom was described by the Roman historian Appian in 27 B.C.E., Appian wrote about the wound that Mithradates suffered, and as he was near death, his Scythian doctor administered a small amount of steppe viper (Vipera renardi) venom to stop the profuse bleeding and the venom caused the blood to clot which saved his life [79].

Up until the late twentieth century, venoms from a wide range of animals were used as traditional remedies in small doses. As modern medicine advanced, investigators were able to identify compounds that could have therapeutic potential [80]. Venoms are complex mixtures of peptides, proteins, and enzymes. With successful isolation, these compounds are highly selective and can be used in a safe manner as a therapeutic [81]. Such drugs as Capoten to treat hypertension, Byetta to treat type 2 diabetes mellitus, Prialt to manage severe chronic pain, and Chlorotoxin to identify tumors in the CNS have all been developed from the venoms of snakes, snails, lizards, and scorpions [82]. The hemostatic nature of many venoms makes them a prime candidate to expand PC therapy for preventing hemorrhage [80]. Moreover, many of the proteins found in venoms cause a rapid and prolonged onset of edema in a dose-dependent manner. Proteins that elicit inflammatory mechanisms similar to those of SBI are optimal for PC. Here, we describe the therapeutic potential of a specific protein isolated from one of the four major snake venom protein families, and proteins from two additional protein families.

\section{Pseudechis papuanus venom-derived phospholipase} $\mathbf{A}_{\mathbf{2}}$ (PLA $\mathbf{P L}_{\mathbf{2}}$ ) The Papuan black snake, P. papuanus, is an elapid species endemic to Papua New Guinea. Recent proteomic analysis showed that the venom proteome is dominated by a variety of PLA $\mathrm{PL}_{2}$ isoforms, which together account for approximately $90 \%$ of the venom proteins, with the remainder including a short neurotoxic threefinger toxins (3FTx; 3.1\%), PIII-snake venom metalloproteinase (SVMPs; 2.8\%), cysteine-rich secretory proteins (CRISPs; $2.3 \%$ ), and L-amino acid oxidase (LAAO; 1.6\%) molecules [83]. Venom activities including intravascular hemolysis, pulmonary congestion and edema, anticoagulation, and death are believed to be caused primarily by the PLA $\mathrm{P}_{2}$ isoforms. After Kim et al. [45] and Wang et al. $[67,68]$ demonstrated that venoms with PLA $_{2}$ can attenuate brain edema and improve neurological outcomes, we became interested in investigating a pure $\mathrm{PLA}_{2}$ therapy. Because of the complex nature of the venoms these investigators used, and also the presence of immunogenic proteins in these venoms, there is a need to study a PLA PLich $_{2}$ venom such as that of $P$. papuanus. Kim et al. [44] further demonstrated that venom with hemorrhagic effects can mitigate intra- and post-operative brain hemorrhage. Because of the unique mixture of inflammatory and platelet-aggregating effects of $P$. papuanus venom, we view this venom as a prime therapy for SBI, which preliminary studies are bearing out.

Snake venom metalloproteinases Snake venom metalloproteinases (SVMPs) are divided into three main classes (PI, PII, and PIII) based on size and domain. SVMPs are $\mathrm{Zn}^{2+}$-dependent endopeptidases with activities usually related to hemorrhaging and disruption of hemostasis [84]. These metalloproteinases cleave a small number of specific zymogens in platelet aggregation and trigger the coagulation cascade. Furthermore, they are known to cause edema, inflammation, and necrosis because of their destructive action on basement membranes [85, 86]. After an ischemic event, there is an increase in matrix metalloproteinases (MMPs) both in the blood 
and brain, with the most studied ones being MMP-9 and MMP-2 [87]. These two proteins are thought to be responsible for the degradation of collagen IV, a major component of the basal lamina, ultimately leading to BBB disruption. SVMPs have strong structural similarities with both mammalian matrix metalloproteinase and members of a disintegrin and metalloproteinase (ADAMs) groups [88]. Studies have demonstrated that SVMPs induce formation of blisters in the dermis and infiltration of leukocytes at the site of injection. Injection of SVMPs was also associated with degranulation of mast cells (which lead to histamine release, inducing vascular permeability and vasodilatation leading to extravasation), and the expression of messenger RNA (mRNA) encoding for tumor necrosis factor (TNF), interleukin-1 (IL-1), and interleukin-6 (IL-6) by elicited macrophages $[86,89]$.

Of particular interest is the ability of SVMPs to activate the complement system. Activation of anaphylatoxins C3a and C5a serve as powerful chemoattractants for leukocytes and have been shown to damage the BBB in $\mathrm{ICH}$ [90]. Anaphylatoxins induce rapid activation of endothelial cells and resident microglia, as well as infiltration of granulocytes, in the perihematomal region [91, 92]. Activated microglia secrete inflammatory cytokines, such as TNF- $\alpha$ and IL-1 $\beta$, thereby amplifying the inflammatory response [93]. The formation of the membrane attack complex (MAC) causes the lysis of erythrocytes and exacerbates brain edema and oxidative stress due in part to the breakdown of hemoglobin $[94,95]$. Collectively, SVMPs can trigger similar inflammatory pathways that have been implicated in SBI, causing an endogenous response to protect against future insult.

Snake venom serine proteases Snake venom serine proteases (SVSPs) comprise a group of well-studied toxins which are known for being the primary contributor affecting the hemostatic system [96]. Serine proteases are abundant in snake venoms and have been identified in venoms mainly from the subfamilies Crotalinae (genera Agkistrodon, Crotalus, Lachesis, Trimeresurus), Viperinae (Cerastes cerastes, Cerastes vipera, Bitis gabonica), and Colubrinae (Dipholidustypus) [96]. SVSPs cause interference and imbalances of the hemostatic system by promoting specific proteolysis at various key points of the coagulation cascade [97, 98]. Furthermore, SVSPs have been demonstrated to induce significant edema via the metabolism of arachidonic acid (AA), involving proteaseactivated receptors (PARs), protein kinase $\mathrm{c}$ (PKC), phospholipase C (PLC), and cyclooxygenase-2 (COX-2) receptors, and also induce a significant increase in malondialdehyde (MDA) levels [99]. Costa et al. [99] demonstrated that SVSPs may be involved in the degradation of PAR1 and PAR2, which activate PLC and PKC to mobilize AA, while increasing oxidative stress. SVSPs trigger inflammatory cascades that have been implicated in SBI pathophysiology that SVMPs and PLA $_{2}$ might not successfully trigger. Using SVPSs as a preconditioning agent may also attenuate the injury due to SBI.

\section{Conclusions}

The anticipatable timing of surgical brain injury provides a unique opportunity for preemptive intervention, but clinical medicine has yet to utilize preconditioning methods to protect the brain from SBI. To date, SBI is often left to resolve on its own, and currently, there is no treatment available to alleviate it, which is in large part due to our poor understanding of the pathophysiology.

Before any of these therapies can be tested in clinical trials, further in vivo experimental studies are needed to evaluate preconditioning agents and to provide a better mechanistic understanding of SBI pathophysiology. The pathophysiological understanding of SBI remains sparse compared to that of other stroke or brain injury models. To date, SBI studies have implicated certain pro-inflammatory pathways and cellular targets. Further studies are needed to expand on upstream and downstream mediators of these signaling pathways in the pathogenesis of SBI. Secondary injury processes of SBI include neuroinflammation, metabolic disturbances, apoptosis, ischemia, oxidative stress, and BBB disruption. Moreover, studies are needed with isolated snake venom metalloproteinase and snake venom serine proteases. Whole venoms have been investigated in SBI models and have been efficacious in small quantities. Purified proteins have been extensively studied, and their properties suggest they could provide further neuroprotection. Despite their toxic effects, it is well established that some components from snake venoms present beneficial effects when acting alone in small quantities.

Lastly, studies that factor in sex and age are also needed. In TBI, it is believed that sex plays a role in outcomes and response to TBI treatments. Microglia, which are the major resident immune cells of the brain, have sexually dimorphic roles in the development and maintenance of the normal brain and have different responses in TBI between males and females [100]. Age at the time of injury is a major factor in the functional recovery of patients. Investigators demonstrated that there is an increase in infiltration of peripheral monocytes at the site of injury in aged rates compared to young animals in a TBI model [101]. As we continue to investigate SBI and its pathophysiology, there is hope that additional therapeutic targets may arise. Venom-derived proteins applied in a preconditioning manner $[102,103]$ is a promising translational therapy and could be a major step forward in how we treat patients.

\section{Abbreviations}

AA: Arachidonic acid; ADAM: A disintegrin and metalloproteinase; AQ-

4: Aquaporin-4; BBB: Blood-brain barrier; BWC: Brain water content;

CDc42: Cell division cycle protein 42; CRISPs: Cysteine-rich secretory proteins; 
CNS: Central nervous system; CSF: Cerebral spinal fluid; COX2: Cyclooxygenase-2; FGF2: Fibroblast growth factor 2; GM-CSF: Granulocytemacrophage colony-stimulating factor; GSH: Glutathione; HIF1A: Hypoxiainducible factor 1-a; IBA-1: Ionized calcium binding adaptor molecule 1; ICP: Intracranial pressure; IL-1/6/10: Interleukin-1/6/10; KO: Knockout; LAAO: Lamino acid oxidase; LPO: Lipid peroxidation; MAC: Membrane attack complex; MBP: Myelin basic protein; MDA: Malondialdehyde; MMP: Matrix metalloproteinase; MPO: Myeloperoxidase; mRNA: messenger RNA; NFKB: Nuclear factor kappa light chain enhancer of activated B; NO: Nitric oxide; NS: Neurological score; PARs: Protease-activated receptors;

PC: Preconditioning; PDGF: Platelet derived growth factor; PKC: Protein kinase $C_{;}$PLA 2 : Phospholipase $A_{2}$; PLC: Phospholipase C; SBI: Surgical brain injury SVMPS: Snake venom metalloproteinase; SVSPs: Snake venom serine protease; TGF- $\beta 1$ : Transforming growth factor beta 1; TBI: Traumatic brain injury; TNF: Tumor necrosis factor; 3FTx: Three-finger toxin; VEGF: Vascular endothelial growth factor; ZO-1: Zonula occludens-1

\section{Acknowledgements}

Figures 1 and 2 are created using BioRender.com

\section{Authors' contributions}

ZT drafted the manuscript. PS and WH helped revise the manuscript. ZT, PS $\mathrm{WH}$, and $\mathrm{JZ}$ conceived of this study. All authors read and approved the final manuscript.

\section{Funding}

This study was partially supported by NIH R01BS084921 to J.H.Z.

\section{Availability of data and materials}

Not applicable.

\section{Ethics approval and consent to participate}

Not applicable.

\section{Consent for publication}

Not applicable.

\section{Competing interests}

The authors declare that they have no competing interests.

\section{Author details}

${ }^{1}$ Department of Earth and Biological Sciences, School of Medicine, Loma Linda University, Loma Linda, CA 92354, USA. ²Department of Physiology and Pharmacology, School of Medicine, Loma Linda University, Loma Linda CA 92354, USA. ${ }^{3}$ Department of Anesthesiology, School of Medicine, Loma Linda University, Loma Linda, CA 92354, USA.

\section{Received: 28 August 2019 Accepted: 14 November 2019} Published online: 16 December 2019

\section{References}

1. Manninen PH, Raman SK, Boyle K, El-Beheiry H. Early postoperative complications following neurosurgical procedures. Can J Anesth. 1999;46:7

2. Solaroglu I, Beskonakli E, Kaptanoglu E, Okutan O, Ak F, Taskin Y. Transcortical-transventricular approach in colloid cysts of the third ventricle: surgical experience with 26 cases. Neurosurg Rev. 2004;27:89-92.

3. Deletis $V$, Sala $F$. The role of intraoperative neurophysiology in the protection or documentation of surgically induced injury to the spinal cord. Ann NY Acad Sci. 2001;939:137-44.

4. Gerzeny M, Cohen AR. Advances in endoscopic neurosurgery. AORN J. 1998; 67:957-65.

5. Bruder N, Ravussin P. Recovery from anesthesia and postoperative extubation of neurosurgical patients: a review. J Neurosurg Anesth. 1999;11: 282-93.

6. Lo W, Bravo T, Jadhav V, Titova E, Zhang JH, Tang J. NADPH oxidase inhibition improves neurological outcomes in surgically-induced brain injury. Neurosci Let. 2007;414:228-32.

7. Hyong A, Jadhav V, Lee S, Tong W, Rowe J, Zhang JH, Tang J. Rosiglitazone, a PPAR gamma agonist, attenuates inflammation after surgical brain injury in rodents. Brain Res. 2008;1215:218-24.
8. Ayer RE, Jafarian N, Chen W, Applegate RL, Colohan AR, Zhang JH. Preoperative mucosal tolerance to brain antigens and $\mathrm{a}$ neuroprotective immune response following surgical brain injury. J Neurosurg. 2012;116:246-53.

9. Lekic T, Rolland W, Manaenko A, Krafft PR, Kamper JE, Suzuki H, Hartman RE, Tang J, Zhang JH. Evaluation of the hematoma consequences, neurobehavioral profiles, and histopathology in a rat model of pontine hemorrhage. J Neurosurg. 2013;118:465-77.

10. Sulejczak D, Grieb P, Walski M, Frontczak-Baniewicz M. Apoptotic death of cortical neurons following surgical brain injury. Folia Neuropathol. 2008:46:213-9.

11. Dewan MC, Rattani A, Fieggen G, Arraez MA, Servadei F, Boop FA, Johnson WD, Warf BC, Park KB. Global neurosurgery: the current capacity and deficit in the provision of essential neurosurgical care. Executive Summary of the Global Neurosurgery Initiative at the Program in Global Surgery and Socia Change. J Neurosurg. 2018;130:1055-64.

12. Menon D. Critical care medicine: management of raised intracranial pressure. Oxford Textbook of Medicine. 2003;2:1256.

13. Gomes JA, Stevens RD, Lewin JJ, Mirski MA, Bhardwaj A. Glucocorticoid therapy in neurologic critical care. Crit Care Med. 2005;33:1214-24.

14. Jadhav $\mathrm{V}$, Zhang $\mathrm{JH}$. Surgical brain injury: prevention is better than cure Front Biosci. 2008;13:3793-7.

15. Studdert DM, Mello MM, Sage WM, DesRoches CM, Peugh J, Zapert K Brennan TA. Defensive medicine among high-risk specialist physicians in a volatile malpractice environment. JAMA-J Am Med Assoc. 2005;293:2609-17.

16. Mello MM, Studdert DM, DesRoches CM, Peugh J, Zapert K, Brennan TA, Sage WM. Effects of a malpractice crisis on specialist supply and patient access to care. Ann Surg. 2005;242:621.

17. Pownall M. Tissue damage is commonest cause of surgical negligence suits. BMJ-Brit Med J. 1999 Mar 13:318:692.

18. Tataranu L, Gorgan MR, Ene BO, Ciubotaru V, Sandu A, Dediu A. Neuroprotection against surgically induced brain injury. Rom Neurosurg. 2007; 15:3-12.

19. Frontczak-Baniewicz M, Gordon-Krajcer W, Walski M. The immature endothelial cell in new vessel formation following surgical injury in rat brain. Neuroendocrinol Lett. 2006:27:539-46.

20. McDonald SJ, Sun M, Agoston DV, Shultz SR. The effect of concomitant peripheral injury on traumatic brain injury pathobiology and outcome. J Neuroinflamm. 2016;13:90.

21. Abbott NJ, Patabendige AA, Dolman DE, Yusof SR, Begley DJ. Structure and function of the blood-brain barrier. Neurobiol Dis. 2010;37:13-25.

22. Abbott NJ, Rönnbäck L, Hansson E. Astrocyte-endothelial interactions at the blood-brain barrier. Nat Rev Neurosci. 2006;7:41

23. Alvarez JI, Teale JM. Breakdown of the blood brain barrier and bloodcerebrospinal fluid barrier is associated with differential leukocyte migration in distinct compartments of the CNS during the course of murine NCC. J Neuroimm. 2006 1;173(1-2):45-55.

24. Amouzeshi A, Pourbagher-Shahri AM. Effects of endocannabinoid system, synthetic and nonsynthetic cannabinoid drugs on traumatic brain injury outcome: a narrative review. J Surg Trauma. 2019;7:3-14.

25. Campbell M, Hanrahan F, Gobbo OL, Kelly ME, Kiang AS, Humphries MM, Nguyen AT, Ozaki E, Keaney J, Blau CW, Kerskens CM. Targeted suppression of claudin-5 decreases cerebral oedema and improves cognitive outcome following traumatic brain injury. Nat Commun. 2012;3:849.

26. Raghupathi R. Cell death mechanisms following traumatic brain injury. Brain Pathol. 2004;14:215-22.

27. Rosenberg GA, Yang Y. Vasogenic edema due to tight junction disruption by matrix metalloproteinases in cerebral ischemia. Neurosurg Focus. 2007:22:1-9.

28. Schaefer PW, Buonanno FS, Gonzalez RG, Schwamm LH. Diffusion-weighted imaging discriminates between cytotoxic and vasogenic edema in a patient with eclampsia. Stroke. 1997;28:1082-5.

29. Liang D, Bhatta S, Gerzanich V, Simard JM. Cytotoxic edema: mechanisms of pathological cell swelling. Neurosurg Focus. 2007;22:1-9.

30. Unterberg AW, Stover J, Kress B, Kiening KL. Edema and brain trauma Neuroscience. 2004:129:1019-27.

31. Marmarou A, Barzo P, Fatouros P, Yamamoto T, Bullock R, Young H. Traumatic brain swelling in head injured patients: brain edema or vascular engorgement? In: James HE, Marshall LF, Raulen HJ, Baethmann A, Marmarou A, Ito U et al, editors. Brain edema X. Acta Neur S 1997: 70:6870. Vienna: Springer. 
32. Marmarou A, Fatouros PP, Barzó P, Portella G, Yoshihara M, Tsuji O, Yamamoto T, Laine F, Signoretti S, Ward JD, Bullock MR. Contribution of edema and cerebral blood volume to traumatic brain swelling in headinjured patients. J Neurosurg. 2000;93:183-93.

33. Matchett G, Hahn J, Obenaus A, Zhang J. Surgically induced brain injury in rats: the effect of erythropoietin. J Neurosci Meth. 2006;158:234-41.

34. Yamaguchi M, Jadhav V, Obenaus A, Colohan A, Zhang JH. Matrix metalloproteinase inhibition attenuates brain edema in an in vivo model of surgically-induced brain injury. Neurosurgery. 2007;61:1067-76.

35. Jadhav V, Yamaguchi M, Obenaus A, Zhang JH. Matrix metalloproteinase inhibition attenuates brain edema after surgical brain injury. In: Steiger HJ, editor. Acta Neur S 2008;102:357-361. Vienna: Springer.

36. Mokri B. The Monro-Kellie hypothesis: applications in CSF volume depletion. Neurology. 2001;56:1746-8.

37. Sherchan P, Huang L, Akyol O, Reis C, Tang J, Zhang JH. Recombinant Slit2 reduces surgical brain injury induced blood brain barrier disruption via Robo4 dependent Rac1 activation in a rodent model. Sci Rep-UK. 2017;7:746.

38. Sherchan P, Huang L, Wang Y, Akyol O, Tang J, Zhang JH. Recombinant Slit2 attenuates neuroinflammation after surgical brain injury by inhibiting peripheral immune cell infiltration via Robo1-srGAP1 pathway in a rat model. Neurobiol Dis. 2016;85:164-73.

39. Petty MA, Lo EH. Junctional complexes of the blood-brain barrier: permeability changes in neuroinflammation. Prog Neurobiol. 2002;68: $311-23$.

40. Yoshimura A, Shichita T. Post-ischemic inflammation in the brain. Front Immunol. 2012;3:132

41. Zakhary G, Sherchan P, Li Q, Tang J, Zhang JH. Modification of kynurenine pathway via inhibition of kynurenine hydroxylase attenuates surgical brain injury complications in a male rat model. J Neurosci Res. 2019;doi:10.1002/ jnr.24489.

42. Yang W, Liu Y, Liu B, Tan H, Lu H, Wang H, Yan H. Treatment of surgical brain injury by immune tolerance induced by intrathymic and hepatic portal vein injection of brain antigens. Sci Rep-UK. 2016;6:32030.

43. Xiong $Y$, Mahmood A, Chopp M. Current understanding of neuroinflammation after traumatic brain injury and cell-based therapeutic opportunities. Chinese J Traumatol. 2018;21:137-51.

44. Kim CH, McBride DW, Raval R, Sherchan P, Hay KL, Gren EC, Kelln W, Lekic T, Hayes WK, Bull BS, Applegate R. Crotalus atrox venom preconditioning increases plasma fibrinogen and reduces perioperative hemorrhage in a rat model of surgical brain injury. Sci Rep-UK. 2017;7:40821.

45. Kim CH, McBride DW, Sherchan P, Person CE, Gren EC, Kelln W, Lekic T, Hayes WK, Tang J, Zhang JH. Crotalus helleri venom preconditioning reduces postoperative cerebral edema and improves neurological outcomes after surgical brain injury. Neurobiol Dis. 2017;107:66-72.

46. Lo W, Bravo T, Jadhav V, Titova E, Zhang JH, Tang J. NADPH oxidase inhibition improves neurological outcomes in surgically-induced brain injury. Neurosci Let. 2007;414:228-32.

47. Lee $S$, Jadhav V, Ayer R, Rojas H, Hyong A, Lekic T, Stier G, Martin R, Zhang $\mathrm{JH}$. The antioxidant effects of melatonin in surgical brain injury in rats. In: Steiger HJ, editor. Acta Neur S 2008;102:367-371. Vienna: Springer.

48. Lee $S$, Jadhav V, Ayer RE, Rojas H, Hyong A, Lekic T, Tang J, Zhang JH. Dual effects of melatonin on oxidative stress after surgical brain injury in rats. J Pineal Res. 2009;46:43-8.

49. Bravo TP, Matchett GA, Jadhav V, Martin RD, Jourdain A, Colohan A, Zhang $\mathrm{JH}$, Tang J. Role of histamine in brain protection in surgical brain injury in mice. Brain Res. 2008;1205:100-7.

50. Di F, Yan-ting G, Hui L, Tao T, Zai-hua X, Xue-ying S, Hong-li X, Yun-jie W. Role of aminoguanidine in brain protection in surgical brain injury in rat. Neurosci Lett. 2008;448:204-7.

51. Hao W, Wu XQ, Xu RT. The molecular mechanism of aminoguanidinemediated reduction on the brain edema after surgical brain injury in rats. Brain Res. 2009:1282:156-61.

52. Jadhav V, Ostrowski RP, Tong W, Matus B, Jesunathadas R, Zhang JH. Cyclooxygenase-2 mediates hyperbaric oxygen preconditioning-induced neuroprotection in the mouse model of surgical brain injury. Stroke. 2009; 40:3139-42.

53. Westra D, Chen W, Tsuchiyama R, Colohan A, Zhang JH. Pretreatment with normobaric and hyperbaric oxygenation worsens cerebral edema and neurologic outcomes in a murine model of surgically induced brain injury. In: Zhang J., Colohan A, editors. Intracerebral hemorrhage research. Acta Neur S 2011;111:243-251. Springer, Vienna.
54. Khatibi NH, Jadhav V, Saidi M, Chen W, Martin R, Stier G, Tang J, Zhang JH. Granulocyte colony-stimulating factor treatment provides neuroprotection in surgically induced brain injured mice. In: Zhang J., Colohan A, editors. Intracerebral hemorrhage research. Acta Neur S 2011;111:265-269. Springer, Vienna..

55. Khatibi NH, Jadhav V, Matus B, Fathali N, Martin R, Applegate R, Tang J, Zhang JH. Prostaglandin E 2 EP 1 Receptor inhibition fails to provide neuroprotection in surgically induced brain-injured mice. In: Zhang J., Colohan A, editors. Intracerebral hemorrhage research. Acta Neur S 2011; 111:277-281. Springer, Vienna.

56. Jafarian N, Ayer R, Eckermann J, Tong W, Applegate RL, Stier G, Martin R, Tang J, Zhang JH. Mucosal tolerance to brain antigens preserves endogenous TGF $\beta-1$ and improves neurological outcomes following experimental craniotomy. In: Zhang J., Colohan A, editors. Intracerebral hemorrhage research. Acta Neur S 2011;111:283-287. Springer, Vienna.

57. Eckermann JM, Chen W, Jadhav V, Hsu FP, Colohan AR, Tang J, Zhang JH. Hydrogen is neuroprotective against surgically induced brain injury. Med Gas Res. 2011;1:7.

58. Benggon $\mathrm{M}$, Chen $\mathrm{H}$, Applegate $\mathrm{R}$, Martin $\mathrm{R}$, Zhang $\mathrm{JH}$. The effect of dexmedetomidine on brain edema and neurological outcomes in surgical brain injury in rats. Anesth Analg. 2012;115:154.

59. Manaenko A, Sun X, Kim CH, Yan J, Ma Q, Zhang JH. PAR-1 antagonist SCH79797 ameliorates apoptosis following surgical brain injury through inhibition of ASK1-JNK in rats. Neurobiol Dis. 2013:50:13-20.

60. Zheng Y, Kang J, Liu B, Fan W, Wu Q, Luo K, Yan H. An experimental study on thymus immune tolerance to treat surgical brain injury. Chinese Med J. 2014;127:685-90.

61. Xu FF, Sun $S$, Ho AS, Lee D, Kiang KM, Zhang XQ, Wang AM, Wu EX, Lui WM, Liu BY, Leung GK. Effects of progesterone vs. dexamethasone on brain oedema and inflammatory responses following experimental brain resection. Brain Injury. 2014;28:1594-601.

62. Huang KF, Hsu WC, Hsiao JK, Chen GS, Wang JY. Collagenglycosaminoglycan matrix implantation promotes angiogenesis following surgical brain trauma. BioMed Res Int. 2014;2014:627409.

63. Huang L, Sherchan P, Wang Y, Reis C, Applegate RL, Tang J, Zhang JH. Phosphoinositide 3-kinase gamma contributes to neuroinflammation in a rat model of surgical brain injury. J Neurosci. 2015;35:10390-401.

64. Huang L, Woo W, Sherchan P, Khatibi NH, Krafft P, Rolland W, Applegate RL, Martin RD, Zhang J. Valproic acid pretreatment reduces brain edema in a rat model of surgical brain injury. In: Applegate R., Chen G., Feng H., Zhang J., editors. Brain Edema XVI. Acta Neur S 2016;121:305-310. Cham: Springer.

65. Komanapalli ES, Sherchan P, Rolland W, Khatibi N, Martin RD, Applegate RL, Tang J, Zhang JH. Epsilon aminocaproic acid pretreatment provides neuroprotection following surgically induced brain injury in a rat model. In: Applegate R., Chen G., Feng H., Zhang J., editors. Brain Edema XVI. Acta Neur S 2016;121:311-315. Cham: Springer.

66. Pakkianathan C, Benggon M, Khatibi NH, Chen H, Marcantonio S, Applegate $\mathrm{R}$, Tang J, Zhang J. Propofol pretreatment fails to provide neuroprotection following a surgically induced brain injury rat model. In: Applegate R., Chen G., Feng H., Zhang J., editors. Brain Edema XVI. Acta Neur S 2016;121:323327. Cham: Springer.

67. Wang Y, Sherchan P, Huang L, Akyol O, McBride DW, Zhang JH. Naja sputatrix venom preconditioning attenuates neuroinflammation in a rat model of surgical brain injury via PLA2/5-LOX/LTB4 cascade activation. Sci Rep-UK. 2017;7:5466.

68. Wang Y, Sherchan P, Huang L, Akyol O, McBride DW, Zhang JH. Multiple mechanisms underlying neuroprotection by secretory phospholipase $\mathrm{A}_{2}$ preconditioning in a surgically induced brain injury rat model. Exp Neurol. 2018;300:30-40.

69. Xiao Y, Li G, Chen Y, Zuo Y, Rashid K, He T, Feng H, Zhang JH, Liu F. Milk fat globule-epidermal growth factor-8 pretreatment attenuates apoptosis and inflammation via the integrin- $\beta 3$ pathway after surgical brain injury in rats. Front Neurol. 2018;9:96.

70. Akyol O, Sherchan P, Yilmaz G, Reis C, Ho WM, Wang Y, Huang L, Solaroglu I, Zhang JH. Neurotrophin-3 provides neuroprotection via TrkC receptor dependent pErk5 activation in a rat surgical brain injury model. Exp Neurol. 2018;307:82-9.

71. Chen JH, Hsu WC, Huang KF, Hung CH. Neuroprotective effects of collagenglycosaminoglycan matrix implantation following surgical brain injury. Mediat Inflamm. 2019;2019:6848943. 
72. Huang KF, Hsu W-C, Hsiao JK, Chen GS, Wang JY. Collagenglycosaminoglycan matrix implantation promotes angiogenesis following surgical brain trauma. BioMed Res Int. 2014;2014:672409.

73. Li Z, Liu W, Kang Z, Lv S, Han C, Yun L, Sun X, Zhang JH. Mechanism of hyperbaric oxygen preconditioning in neonatal hypoxia-ischemia rat model. Brain Res. 2008;1196:151-6.

74. Wad K, Ito M, Miyazawa T, Katoh H, Nawashiro H, Shima K, Chigasaki H. Repeated hyperbaric oxygen induces ischemic tolerance in gerbil hippocampus. Brain Res. 1996;740:15-20.

75. Yunoki M, Nishio S, Ukita N, Anzivino MJ, Lee KS. Hypothermic preconditioning induces rapid tolerance to focal ischemic injury in the rat. Exp Neurol. 2003;181:291-300.

76. Park DH, Kang HY. Abstract TP132: The combination therapy of intravenous mannitol and hypoxic preconditioned stem cells for ischemic stroke. Stroke. 2019;50(Suppl 1):ATP132.

77. Jang MJ, You D, Park JY, Kim K, Aum J, Lee C, Song G, Shin HC, Suh N, Kim YM, Kim CS. Hypoxic preconditioned mesenchymal stromal cell therapy in a rat model of renal ischemia-reperfusion injury: development of optimal protocol to potentiate therapeutic efficacy. Intl I Stem Cells. 2018;1 1:157.

78. Mayor A. Greek fire, poison arrows, and scorpion bombs: biological and chemical warfare in the ancient world. New York: Overlook Press; 2008.

79. Bhattacharjee $P$, Bhattacharyya D. Therapeutic use of snake venom components: a voyage from ancient to modern India. Mini-Rev Org Chem. 2014;11:45-54

80. Pennington MW, Czerwinski A, Norton RS. Peptide therapeutics from venom: current status and potential. Bioorg Med Chem. 2018;26:2738-58.

81. Waheed H, Moin SF, Choudhary MI. Snake venom: from deadly toxins to life-saving therapeutics. Curr Med Chem. 2017;24:1874-91.

82. King $G$, editor. Venoms to drugs: Venom as a source for the development of human therapeutics. Cambridge: Royal Society of Chemistry; 2015.

83. Pla D, Bande BW, Welton RE, Paiva OK, Sanz L, Segura A, Wright CE, Calvete JJ, Gutiérrez JM, Williams DJ. Proteomics and antivenomics of Papuan black snake (Pseudechis papuanus) venom with analysis of its toxicological profile and the preclinical efficacy of Australian antivenoms. J Proteomics. 2017;150:201-15.

84. Fox J, Gutiérrez J. Understanding the snake venom metalloproteinases: an interview with Jay Fox and José María Gutiérrez. Toxins. 2017;9:33.

85. Camacho E, Escalante T, Remans K, Gutiérrez JM, Rucavado A. Site mutation of residues in a loop surrounding the active site of a PI snake venom metalloproteinase abrogates its hemorrhagic activity. Biochem Bioph Res Co. 2019;512:859-63

86. Cardoso FC, Ferraz CR, Arrahman A, Xie C, Casewell NR, Lewis RJ, Kool J. Multifunctional toxins in snake venoms and therapeutic implications: from pain to hemorrhage and necrosis. Front Ecol Evol. 2019;7:218.

87. Rempe RG, Hartz AM, Bauer B. Matrix metalloproteinases in the brain and blood-brain barrier: versatile breakers and makers. J Cereb Blood F Met. 2016:36:1481-507.

88. Lambrecht BN, Vanderkerken $M$, Hammad $H$. The emerging role of ADAM metalloproteinases in immunity. Nat Rev Immunol. 2018;18:745-58.

89. Prezoto BC, Kato EE, Gonçalves LR, Sampaio SC, Sano-Martins IS. Elevated plasma levels of hepatocyte growth factor in rats experimentally envenomated with Bothrops jararaca venom: role of snake venom metalloproteases. Toxicon. 2019;162:9-14.

90. Ducruet AF, Zacharia BE, Hickman ZL, Grobelny BT, Yeh ML, Sosunov SA, Connolly ES Jr. The complement cascade as a therapeutic target in intracerebral hemorrhage. Exp Neurol. 2009;219:398-403.

91. Rynkowski MA, Kim GH, Garrett MC, Zacharia BE, Otten ML, Sosunov SA, Komotar RJ, Hassid BG, Ducruet AF, Lambris JD, Connolly ES. C3a receptor antagonist attenuates brain injury after intracerebral hemorrhage. J Cereb Blood F Met. 2009;29:98-107.

92. Aronowski J, Hall CE. New horizons for primary intracerebral hemorrhage treatment: experience from preclinical studies. Neurol Res. 2005;27:268-79.

93. Amura CR, Renner B, Lyubchenko T, Faubel S, Simonian PL, Thurman JM. Complement activation and toll-like receptor-2 signaling contribute to cytokine production after renal ischemia/reperfusion. Mol Immunol. 2012;52:249-57.

94. Xi G, Wagner KR, Keep RF, Hua Y, de Courten-Myers GM, Broderick JP, Brott TG, Hoff JT, Muizelaar JP. Role of blood clot formation on early edema development after experimental intracerebral hemorrhage. Stroke. 1998;29:2580-5.

95. Holers VM, Thurman JM. The alternative pathway of complement in disease: opportunities for therapeutic targeting. Mol Immunol. 2004;41:147-52.
96. Zelanis A, Huesgen PF, Oliveira AK, Tashima AK, Serrano SM, Overall CM. Snake venom serine proteinases specificity mapping by proteomic identification of cleavage sites. J Proteomics. 2015;113:260-7.

97. Amorim F, Menaldo D, Carone S, Silva T, Sartim M, De Pauw E, Quinton L, Sampaio S. New insights on moojase, a thrombin-like serine protease from Bothrops moojeni snake venom. Toxins. 2018;10:500.

98. Braud S, Parry MA, Maroun R, Bon C, Wisner A. The contribution of residues 192 and 193 to the specificity of snake venom serine proteinases. J Biol Chem. 2000;275:1823-8.

99. Costa C, Belchor M, Rodrigues C, Toyama D, de Oliveira M, Novaes D, Toyama M. Edema induced by a Crotalus durissus terrificus venom serine protease (Cdtsp 2) involves the PAR pathway and PKC and PLC activation. Int J Mol Sci. 2018;19:2405.

100. Weinhard L, Neniskyte U, Vadisiute A, di Bartolomei G, Aygün N, Riviere L, Zonfrillo F, Dymecki S, Gross C. Sexual dimorphism of microglia and synapses during mouse postnatal development. Dev Neurobiol. 2018;78:618-26.

101. Timaru-Kast R, Luh C, Gotthardt P, Huang C, Schäfer MK, Engelhard K, Thal SC. Influence of age on brain edema formation, secondary brain damage and inflammatory response after brain trauma in mice. PLOS One. 2012;7:e43829.

102. Li Q, Li J, Zhang L, Wang B, Xiong L. Preconditioning with hyperbaric oxygen induces tolerance against oxidative injury via increased expression of heme oxygenase-1 in primary cultured spinal cord neurons. Life sciences. 2007;80:1087-93.

103. Abati E, Bresolin N, Comi GP, Corti S. Preconditioning and cellular engineering to increase the survival of transplanted neural stem cells for motor neuron disease therapy. Mol Neurobiol. 2019;56:3356-67.

\section{Ready to submit your research? Choose BMC and benefit from:}

- fast, convenient online submission

- thorough peer review by experienced researchers in your field

- rapid publication on acceptance

- support for research data, including large and complex data types

- gold Open Access which fosters wider collaboration and increased citations

- maximum visibility for your research: over $100 \mathrm{M}$ website views per year

At $\mathrm{BMC}$, research is always in progress.

Learn more biomedcentral.com/submissions 